\title{
A Novel Multi-Objective Process Parameter Interval Optimization Method for Steel Production
}

\author{
Yifan Yan (1) and Zhimin Lv* \\ Innovation Center of Steel Technology, University of Science and Technology Beijing, Beijing 100083, China; \\ b20170502@xs.ustb.edu.cn \\ * Correspondence: lvzhimin@nercar.ustb.edu.cn
}

check for updates

Citation: Yan, Y.; Lv, Z. A Novel Multi-Objective Process Parameter Interval Optimization Method for Steel Production. Metals 2021, 11, 1642. https://doi.org/10.3390/ met11101642

Received: 12 September 2021

Accepted: 12 October 2021

Published: 15 October 2021

Publisher's Note: MDPI stays neutral with regard to jurisdictional claims in published maps and institutional affiliations.

Copyright: (c) 2021 by the authors. Licensee MDPI, Basel, Switzerland. This article is an open access article distributed under the terms and conditions of the Creative Commons Attribution (CC BY) license (https:// creativecommons.org/licenses/by/ $4.0 /)$.

\begin{abstract}
Customized small batch orders and sustainable development requirements pose challenges for product quality control and manufacturing process optimization for steel production. Building a multi-quality objective process parameter optimization method that converts the original single target optimization into multi-objective interval capability optimization has become a new method to ensure product quality qualification rate and reduce production costs. Aiming at the multi-quality objective control problem of plate products, we proposed a novel multi-objective process parameter interval optimization model (MPPIO) with equipment process control capability and parameter sensitive analysis. The multi-output support vector regression method was used to establish a multi-quality objective prediction model, which was settled as a verification model for the process parameter optimization results based on the particle swarm optimization algorithm (PSO). The process control capability functions of key parameters were fitted based on the real data in production. With these functions, each optimized particle of the classical PSO was converted into the particle beam of the MIPPO. The iteration process was weight controlled by calculating the Morris sensitivity between each input parameter and output index in the multi-quality objective prediction model, and finally the processing control window of each key parameter was determined according to the process parameter optimization results. The experimental results show that the MPPIO model can obtain the optimal parameter optimization results with the maximum processing capacity and meet the customized processing range requirements. The MPPIO model can reduce the difficulty of control and save production costs while ensuring the product properties is qualified.
\end{abstract}

Keywords: hot-rolling; quality control; multi-objective optimization; process control capability; Morris sensitivity analysis; particle swarm optimization algorithm

\section{Introduction}

With the continuous developing of production technology, market requirements and the sustainable development requirements in the iron and steel industry [1], different usage scenarios have put forward differentiated requirements for the lower yield strength (LYS), tensile strength (TS) and other mechanical properties of products. The manufacturing mode of steel enterprises has also changed from the traditional single-variety and high-volume inventory production into multi-variety and small-batch customized order production [2]. Among them, a large number of customized orders are small-scale adjustments based on the actual needs of customers on the basic products.

The ultimate goal of steel companies is to produce high-quality products that meet customer needs with less cost and time [3], and the property qualities of steel products are mainly affected by the composition and processing parameters whose similarities and differences could lead to the crossover of the final property results [4]. In the actual datadriven method, it is necessary to associate the composition and the process parameters of multiple stages with the mechanical properties, so as to predict the mechanical properties based on the composition and process parameters and realize the reverse design and 
optimization of the composition and process parameters according to the customized quality requirements.

Considering the different sensitivity of the composition and parameters to property index, the sensitivity weighted control of process parameters is also meaningful in parameter optimization. Research have proved that artificial neural network, deep learning, support vector regression, extreme learning machine, Lasso regression and other methods had good application effects on regression prediction modeling problems. Hore et al. established a mechanical properties prediction model based on the adaptive neural network provided a real-time quality control platform [5]. Li et al. established an effective prediction model for the tensile strength of hot-rolled strips by adopting the deep learning method to propose a new convolutional network [6]. The data-driven method can provide a basis for properties prediction modeling, and it also provides guidance information as a feedback model in the reverse design and optimization for the process parameters. Xing et al. established an inverse model between hot-rolling product indicators and process parameters to optimize process parameters by using backpropagation neural network [7].

However, challenges often appear in the parameter design and optimization stage [8]. On the one hand, it usually takes a long time to optimize different properties results with the combination of composition and process parameters [9]. On the other hand, the equipment process control capabilities also restrict the level of product quality control [10]; in this situation, it is necessary to transform the original point optimization problem into an interval optimization problem.

The traditional manual experience and trial-and-error production development models will increase the resource waste and costs. In these realistic situations, to maintain the company's competitive advantage and fulfill customer order requirements, data-driven methods and intelligent optimization techniques were combined to build a data-driven model for customized multi-objective manufacturing process optimization [11]. Based on the study of historical production data, different process parameters and chemical compositions were selected to achieve the customized properties requirements. The predictive model established the correlation between the input and the output, and the intelligent algorithm was set as an effective solver to optimize [12].

Many intelligent optimization algorithms based on natural phenomena or natural processes were applied to the processing optimization, such as genetic algorithm (GA), particle swarm optimization (PSO), ant colony optimization (ACO) and bat algorithm (BA) [13]. The artificial neural network method was combined with these genetic algorithms to optimize production process parameters, and it achieved good application effects [14]. In order to speed up the convergence speed, it will also be designed for the characteristics of the algorithm itself besides gradient descent. For example, Wang et al. used Harmony Search as the mutation operator in the update process of the bat algorithm to accelerate the convergence process [15]. In the PSO algorithm, the different sensitivities of particles in each value direction can also be used for weighted control of speed update.

The multi-objective problem was decomposed into multiple single-objective subproblems in some research, and these sub-problems were solved in the order of their weight values [16]. The previous sub-problem solution results were used as the prior data for the remaining sub-problems, so as to achieve the multi-objective optimization [17]. This method might achieve a good solution while the multiple objectives were independent of each other, but there were complex correlation and coupling relationships between the quality indicators of steel products [18], which could not be disassembled into an independent sequential optimization process. In this situation, the multi-quality objective optimization process needed be treated as a holistic optimization problem. Haber et al. achieved good results in the optimization problem of the micro-drilling process by using multi-objective cross-entropy method [19], but the individual particles of the PSO algorithm could be combined with local optimization constraints to improve the solution effect of the interval optimization problem. 
This paper aims at the customer-oriented mechanical property quality objectives and adopts the multi-objective prediction model and PSO with process control capability and sensitivity analysis to construct a process parameter interval optimization model for plate products. This model had been applied to an actual industrial case, and the actual application results proved its effectiveness.

\section{Materials and Methods}

\subsection{Problem Definition}

Steel production involves complex physical and chemical changes, which mainly occur in continuous casting, heating, hot rolling, heat treatment, and cutting [20]. The final property results are affected by the composition and the process parameters of each stage. However, it had the capability to produce reasonable explanatory results by using a physical-driven model. According to the mechanism knowledge or artificial experience, the relationships between the property results and process parameters could be measured. However, the computational complexity of physical-driven model was very costly, which impeded the rapid design and process optimization for customized production. As a comparison, the data-driven model was very convenient and fast, especially for steel companies wherein big data technology had been applied [21]. The product quality prediction model was constructed based on a large amount of historical production data. The prediction model obtained the actual non-linear correlation in the steel production process and could be used to simulate the physical and chemical changes. Therefore, the data-driven quality prediction model could be used as a verification method in the process parameters design and optimization. The final property quality results could be calculated based on production data, and the calculation time and cost would be saved. The relational expression of this data-driven model can be expressed as:

$$
Q=F(D)+\varepsilon
$$

where $Q$ is the quality index, $D$ is the components and process parameters, and $\varepsilon$ is the system error.

In this paper, the components and process parameters are designed and optimized to simultaneously meet the customized multi- objective requirements. It can be expressed mathematically as:

$$
\begin{gathered}
\text { Objective function }: \min \left(\sum_{i=1}^{n}\left|Q_{i}^{\text {Opt }}-Q_{i}^{\text {Aim }}\right|\right) \\
\text { Subject to : } \begin{array}{l}
Q_{i}^{\text {Low }} \leq Q_{i}^{\text {Opt }} \leq Q_{i}^{\text {Up }} \\
D_{k}^{\text {Low }} \leq D_{k}^{\text {Opt }} \leq D_{k}^{\text {Up }}
\end{array}
\end{gathered}
$$

where $Q_{i}^{\mathrm{Opt}}$ and $Q_{i}^{\mathrm{Aim}}$, respectively, represent the optimized results and the requirements of quality index $i(i=1, \ldots, n)$, the value of $Q_{i}^{\text {Opt }}$ is greater than their lower limits $Q_{i}^{\text {Low }}$ and less than the upper limits $Q_{i}^{\mathrm{Up}} ; D_{k}^{\mathrm{Opt}}$ is the content of optimized process parameter $k$ $(k=1, \ldots, g)$; they are both between their lower limits $D_{k}^{\text {Low }}$ and upper limits $D_{k}^{\mathrm{Up}}$.

Otherwise, in the steel production manufacturing process, the process control capability of equipment also affected the final property quality. In this situation, it was necessary to introduce process control capabilities as constraints in the process parameter selection to ensure the stability of product quality. The process control capability was an inherent attribute, which was expressed as the random probability of the possible fluctuations of the set value. The process control capability function of parameter $D_{k}$ was denoted by $f_{\mathrm{Dk}}$, and $M$ associated parameters $D_{k}^{\mathrm{EOpt}}$ were randomly generated by this capability function. Combining the $D_{k}^{\mathrm{EOpt}}$ with other process parameters to generate the random combination, which was used to determine the processing control window of the parameters. The qual- 
ity processing capability results $Q_{i}^{\mathrm{EOpt}}$ of the optimized parameters with the equipment process control capability constraints were obtained.

$$
\begin{gathered}
D_{k}^{\text {EOpt }} \sim\left(D_{k}^{\mathrm{Opt}}, f_{\mathrm{Dk}}\right) \\
D_{k}^{\text {Low }} \leq D_{k}^{\text {EOpt }} \leq D_{k}^{\mathrm{Up}}
\end{gathered}
$$

In the optimization process, the possibility $R_{i}^{\mathrm{Opt}}$ of $Q_{i}^{\mathrm{EOpt}}$ falling within the range of the target property quality $Q_{i}^{\text {Aim }} \pm \delta_{i}$ had to be minimized. According to the customized requirements, the possibility of each property quality should not be lower than $\partial \%$, and the objective function of the parameter optimization result would be modified as:

$$
\begin{aligned}
& \text { Modified objective function : } \max \left(\sum_{i=1}^{n} R_{i}^{\mathrm{Opt}}\right) \\
& \text { Subject to : } R_{i}^{\mathrm{Opt}} \geq \partial \%
\end{aligned}
$$

The calculation method of the confidence degree $R_{i}^{\mathrm{Opt}}$ that the processing results meet the requirement is:

$$
R_{i}^{\mathrm{Opt}}=\int_{Q_{i}^{\mathrm{Aim}}-\delta_{i}}^{Q_{i}^{\mathrm{Aim}}+\delta_{i}} f\left(Q_{i}\right) d Q_{i}
$$

where $f\left(Q_{i}\right)$ is the probability density distribution function of the quality results $Q_{i}^{\text {EOpt }}$. The $\zeta_{i}\left(\zeta_{i} \in[0,1]\right)$ is used to evaluate the deviation of property results corresponding to the maximum values of $f\left(Q_{i}\right)$ and the property requirements $Q_{i}^{\text {Aim }}$. The higher its value is, the better the optimized parameter results meet the requirements.

$$
\zeta_{i}=\frac{\min \left\{\int_{0}^{Q_{i}^{\text {Aim }}} f\left(Q_{i}\right) d Q_{i}, \int_{Q_{i}^{\text {Aim }}}^{+\infty} f\left(Q_{i}\right) d Q_{i}\right\}}{\max \left\{\int_{0}^{Q_{i}^{\text {Aim }}} f\left(Q_{i}\right) d Q_{i}, \int_{Q_{i}^{\text {Aim }}}^{+\infty} f\left(Q_{i}\right) d Q_{i}\right\}}
$$

\subsection{Method}

The manufacturing process parameter optimization model needed to be modeled in two dimensions: the forward prediction from the parameters to the quality results and the reverse design optimization according to the customized requirements to obtain the reasonable parameters. When taking multiple property indicators of steel products as optimization goals, it was necessary to established predictive model by using multiobjective output methods. There were some existing predictive modeling methods being to make a separate prediction for each property index [22]. Although these methods might obtain a certain precision, the independent prediction model could not effectively analyze the correlation and coupling effects between the property indicators. Additionally, it could ultimately lead to the divergence of the optimization model and would not obtain a practical solution. This paper proposes a MPPIO model to simultaneously design and optimize the processing parameters of plate products for multiple objectives, the flow chart of the algorithm is shown in Figure 1. The multi-output support vector regression (MSVR) method was used as the forward mechanical property predictive modeling and the verification model for parameter optimization results. The sensitivity of each parameter to property index was calculated to weighted control the optimization. The equipment process control capabilities were analyzed to calculate the confidence level of each feasible solution. Finally, the MPPIO model obtained the process parameter optimization results with the optimal processing control capacity while ensured the customer's requirements. 


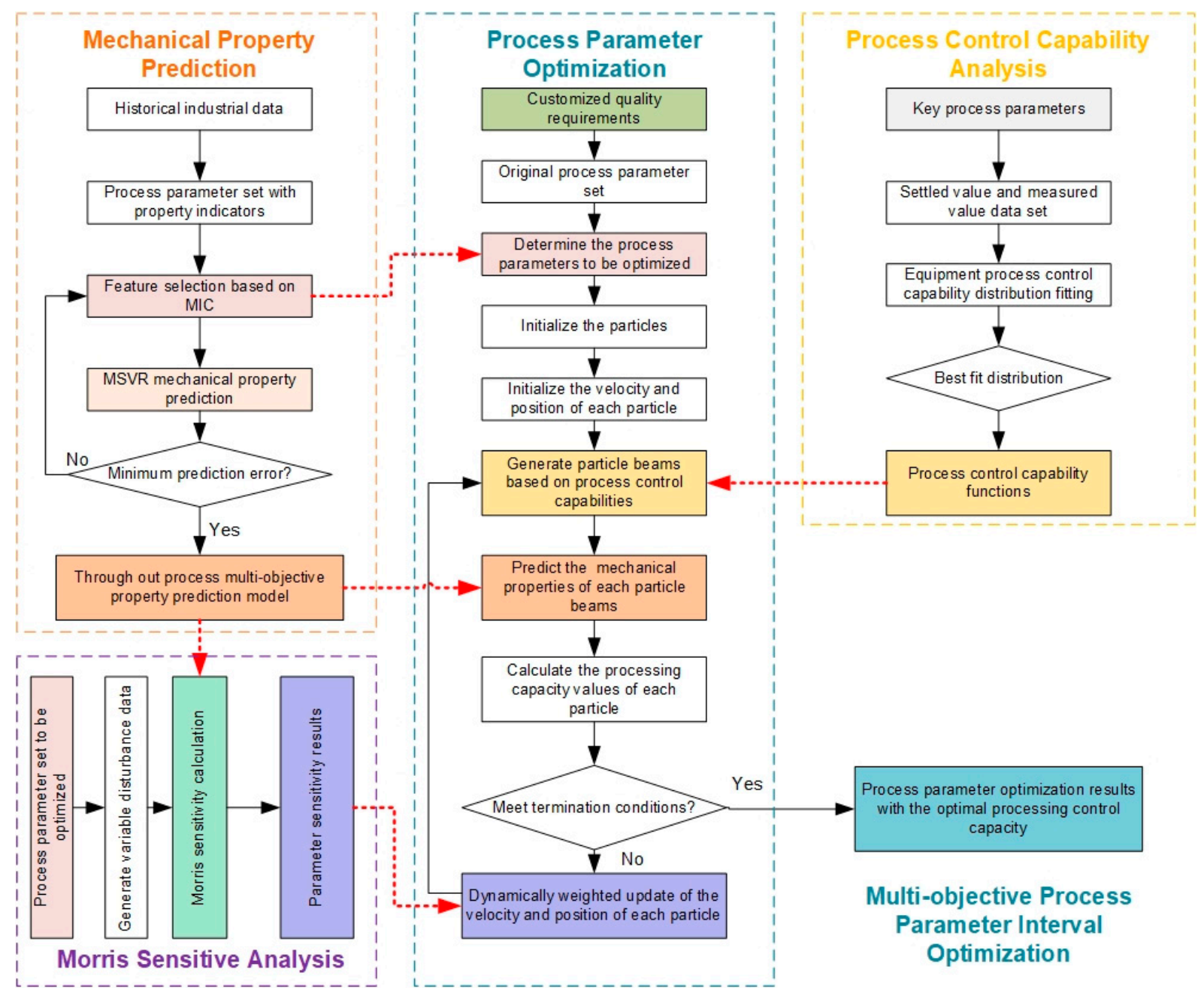

Figure 1. The flow chart of the MPPIO (multi-objective process parameter interval optimization) model. MIC: Maximum information coefficient. MSVR: Multi-output support vector regression.

\subsubsection{Mechanical Property Prediction}

Considering the complex relevance and data characteristics between mechanical property and parameters, the MSVR method was satisfied for modeling. MSVR is the multi-dimensional output form of support vector regression (SVR), and SVR is the form of support vector machine (SVM) in the continuous function domain [23]. The SVM method is a learning mechanism based on the Vapnik-Chervonenkis dimension theory of statistics and the principle of structural risk minimization; SVR transforms a nonlinear problem into a linear problem. It optimizes the promotion ability by balancing the complexity and learning ability of the limited sample information. The input parameters would have data information loss problems such as unfair punishment while directly using SVR to perform regression modeling on multiple objectives. As shown in Figure 2, the square area formed under the two-dimensional output SVR. The data located in area-1 will be punished once, whereas the data in the sensitive area- 2 where multiple objectives overlap will be punished twice. Additionally, the existence of data-b will be punished, but there is no penalty for data-a. In this regard, the hyperplane loss area is used to replace the insensitive loss band, as shown in the circular area in Figure 2, so as to ensure the fairness of the penalty function for each sample. 


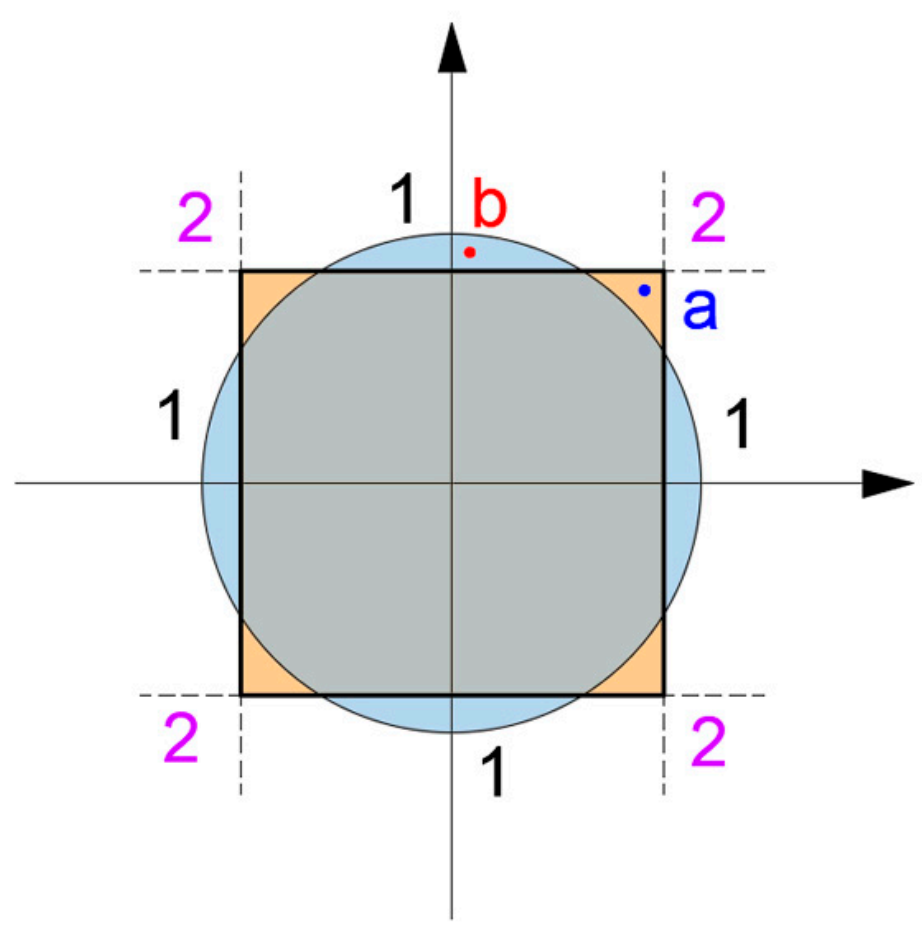

Figure 2. Insensitive zone of two-dimensional target output.

Using MSVR to build the property quality prediction model could effectively balance the accuracy of multiple property predictions and ensure the integrity of data information. Additionally, it had the balancing effect of multi-objective optimization guidance information in the optimization modeling while being used as the verification method.

The quality-related process parameters obtained from multiple stages in steel production were multi-source heterogeneous, high-dimensional, and strong correlation. Considering the lack of sufficient prior knowledge, and the acquired original data might contain many redundant data to avoid information loss as much as possible. These redundant data not only wasted storage and computing resources but might also reduce model performance. It could reduce the dimensionality of the original data by applying feature selection method to reduce costs [24]. The maximum information coefficient (MIC) method was used to calculate the linear or non-linear correlation between each process parameter and property index. The optimal feature subset could help the quality prediction model improve the accuracy and computational efficiency, and it was found by dividing different MIC thresholds for repeated cross-validation.

\subsubsection{Process Parameter Optimization}

PSO is a global search optimization algorithm that simulates bird swarm activities in nature, it considers the solution space as the flight space of the bird colonies. PSO have two flight information including speed and position. The information exchange according to the historical optimal position of the individual and group. Then, the particles are constantly changing their flight direction and speed to approaching the optimal position gradually, and finally complete the optimal results search. The PSO algorithm has a quite simple structure [25]; it can generate high-quality feasible solutions in a short time and has more stable convergence behavior [26]. It has been applicated in solving multi-objective and constraint problems of high-dimensional nonlinear complex engineering systems. Each particle in the population can be easily transformed; in this situation, the particles were converted to particle beams according to the equipment process control capabilities in the MPPIO model, as shown in Figure 3. 


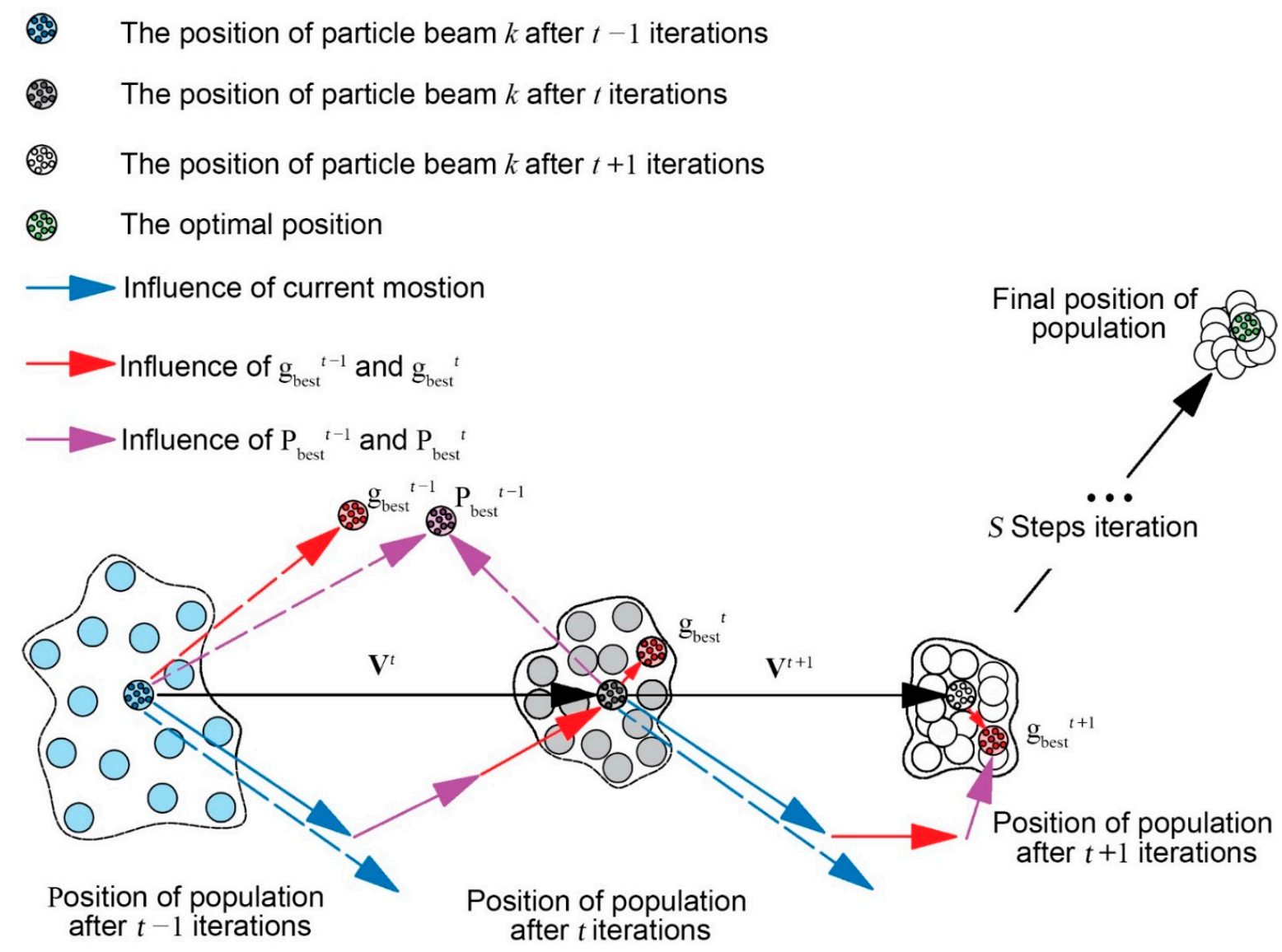

Figure 3. Particle beam optimization process: $\mathrm{g}_{\text {best }}^{t}$ is the group historical optimal position after $t$ iterations; $\mathrm{g}_{\text {best }}^{t-1}$ is the group historical optimal position after $t-1$ iterations; $\mathrm{P}_{\text {best }}^{t}$ is the historical individual optimal position after $t$ iterations; $\mathrm{P}_{\text {best }}^{t-1}$ is the historical individual optimal position after $t-1$ iterations.

The MPPIO model based on PSO is established as follows:

a. Experimental data preparation:

The property targets $Q_{i}^{\text {Aim }} \pm \delta_{i}$ were determined by the customized orders, and the population $X^{\mathrm{Opt}}$ to be optimized and the initial speed $V_{0}$ were randomly initialized according to historical data. Among them, $X^{\mathrm{Opt}}$ was composed of $N$ particles containing g-dimensional process parameters. In the initial population, the particles were converted into particle beams $X_{\mathrm{E}}^{0}$ after processing capability analyzing according to Equation (4).

b. Fitness evaluation:

The fitness value $C_{\mathrm{Fit}}$ of each particle beam were calculated in the current iteration, and it determined the subsequent iteration direction. The average error between the predicted results and the requirements was used as the fitness value in classical PSO:

$$
C_{\text {Fit }}=\frac{1}{n} \sum_{i=1}^{n}\left|\frac{Q_{i}^{\mathrm{Opt}}-Q_{i}^{\mathrm{Aim}}}{Q_{i}^{\mathrm{Aim}}}\right|
$$

The property prediction results $Q_{\mathrm{E}}^{\text {Pre }}$ of each particle beam were predicted firstly by the MSVR model, and the confidence level $R_{i}$ was calculated according to Equation (7). The Equation (8) was used to calculate the deviation value $\zeta_{i}$ between the maximum capacity point of each particle beam and the targets. The confidence level $R_{i}$ and the deviation 
value $\zeta_{i}$ were both in the range of $[0,1]$, and the larger the values were, the better results of optimization gained. Therefore, the fitness value $C_{\mathrm{Fit}}$ in the MPPIO was designed as:

$$
C_{\mathrm{Fit}}=\sqrt{\frac{\sum_{i=1}^{n}\left(R_{i}^{2}+\zeta_{i}^{2}\right)}{2 n}}
$$

According to Equation (10), the fitness value $C_{\mathrm{Fit}}$ was a hypersphere with a maximum radius of 1 , and the closer the value was to 1 , the better the optimization results gained. The historical individual optimal position $X_{\mathrm{P}}$ and group historical optimal position $X_{\mathrm{g}}$ were selected according to the fitness values. In each subsequent iteration, if the current fitness value of the particle beam $i$ was better than its historical optimal value, the particle contents corresponding to the current particle beam was set to the new $X_{\mathrm{P}}$. If the fitness value of the particle beam $i$ was better than the global optimal value, the contents of $X_{\mathrm{g}}$ was updated to the content of the particle $i$.

c. Speed weighted update based on parameter sensitivity:

The speed and position must be within the feasible range $V_{i} \in\left[V^{\min }, V^{\max }\right]$ and $X_{i} \in\left[X^{\min }, X^{\max }\right]$ in each iteration. Particles out of the solution space needed to be corrected: values beyond the minimum of the solution space were replaced by the minimum value, and values over the maximum were replaced by the maximum value. The speed and position of the particles in traditional PSO were updated as follows:

$$
\begin{gathered}
V_{i}=\omega V_{i}+c_{1} r_{1}\left(X_{\mathrm{P}}^{i}-X_{i}\right)+c_{2} r_{2}\left(X_{\mathrm{g}}-X_{i}\right) \\
X_{i}=X_{i}+V_{i}
\end{gathered}
$$

where $\omega$ is the inertia weight that controlled the influence of the previous change on the current value, and it was usually set to dynamically adjust the number of iterations to balance the global search and local search efficiency; $c_{1}$ and $c_{2}$ are the acceleration weights for the subset to advance to $X_{\mathrm{P}}$ and $X_{\mathrm{g}}$, respectively, and they were set as adaptive adjustment based on actual experience. The larger the value of $c_{1}$, the particles are more inclined to their historical optimal position during the optimization process; the larger the value of $c_{2}$, each particle is more inclined to the optimal position in the population. In the traditional PSO, $r_{1}$ and $r_{2}$ are random numbers in the range of $[0,1]$. Similar to $c_{1}$ and $c_{2}$, they are also used to control the change of the distance between its historical optimal position and the population optimal position in every iteration. In each speed update, every parameter carried by the particle was randomly assigned the same value $r_{1}$ and $r_{2}$. Considering each steel production process parameter had different correlations with the property index, the Morris sensitivity analysis method was used to calculate the sensitivity between each input parameter and property index. In the MPPIO model, the sensitivity information was used to reduce the non-critical parameters' interference in the optimization process.

The basic idea of the Morris method was to slightly perturb a certain input parameter within the range of change while kept other parameters unchanged and calculated the output change caused by the change of this parameter [27]. This method could also find important parameters in nonlinear models. It was calculated according to the one variable at a time method that the sensitivities between input parameters and property index of the MSVR model [28]. Firstly, determined the value range of each parameter, the discrete level $p$ and the disturbance $\Delta$, and decomposed each parameter into a value space of g-dimensional with $p$ level: $\left[0, \frac{1}{p-1}, \frac{2}{p-1}, \ldots, 1\right]$; then took values from the value space for each parameter to form base samples, applied perturbation $\Delta$ to each parameter in the base samples to form $g$ perturbation test sets, which needed ensure the parameters were still in the value space; and used MSVR model to predict the results $Q_{i}^{0}$ and $Q_{i}^{\Delta}$ of base sample 
and perturbation sample; finally, the base effects $r_{i}$ of each parameter on the property index were calculated with the current base samples:

$$
r_{i}=\frac{Q_{i}^{\Delta}-Q_{i}^{0}}{\Delta}
$$

After repeatedly calculating the corresponding base effect $M$ times, the absolute average $\mu$ and standard deviation $\sigma(\mu, \sigma \in[0,1])$ of each parameter were calculated. The absolute average $\mu$ of the basis effect represented the sensitivity of the parameter. The standard deviation $\sigma$ represented the sensitivity of this parameter to the synergy of other parameters. The larger the $\mu$ and $\sigma$ value was, the more important this parameter was. Therefore, in the speed control of iterative optimization, the maximum value of $\mu$ and $\sigma$ was used as the weighting coefficient $W$ of the value $r_{1}$ and $r_{2}$ :

$$
W=\left(\max \left(\mu_{1}, \sigma_{1}\right), \ldots, \max \left(\mu_{g}, \sigma_{g}\right)\right)
$$

The speed update method was:

$$
V_{i}=\omega V_{i}+c_{1} r_{1} W \circ\left(X_{\mathrm{P}}-X_{i}\right)+c_{2} r_{2} W \circ\left(X_{\mathrm{g}}-X_{i}\right)
$$

d. Termination condition

The termination condition was set as the upper limit of the number of times $S$ iterations were completed or the optimization results of each particle met the objective function required by Equation (6) before $S$ iterations.

\section{Results and Application}

\subsection{Experimental Preparations}

\subsubsection{Mechanical Property Prediction}

The MPPIO model had been validated by using real data from a factory's plate production. A total of 2631 samples containing 170 production process parameters and two property indices of LYS and TS were obtained from the production database. After data de-duplication and removal of samples with missing values, 1504 samples were obtained at last. The correlations between 170 parameters and property index were calculated by the MIC method, and after multiple divisions of different thresholds for predictive modeling, 112 production parameters with obvious relevance were selected as the optimal feature subset. The obtained property prediction results are shown in Figure 4. The mean absolute percentage errors (MAPE) of the two were $2.79 \%$ and $1.29 \%$, respectively.
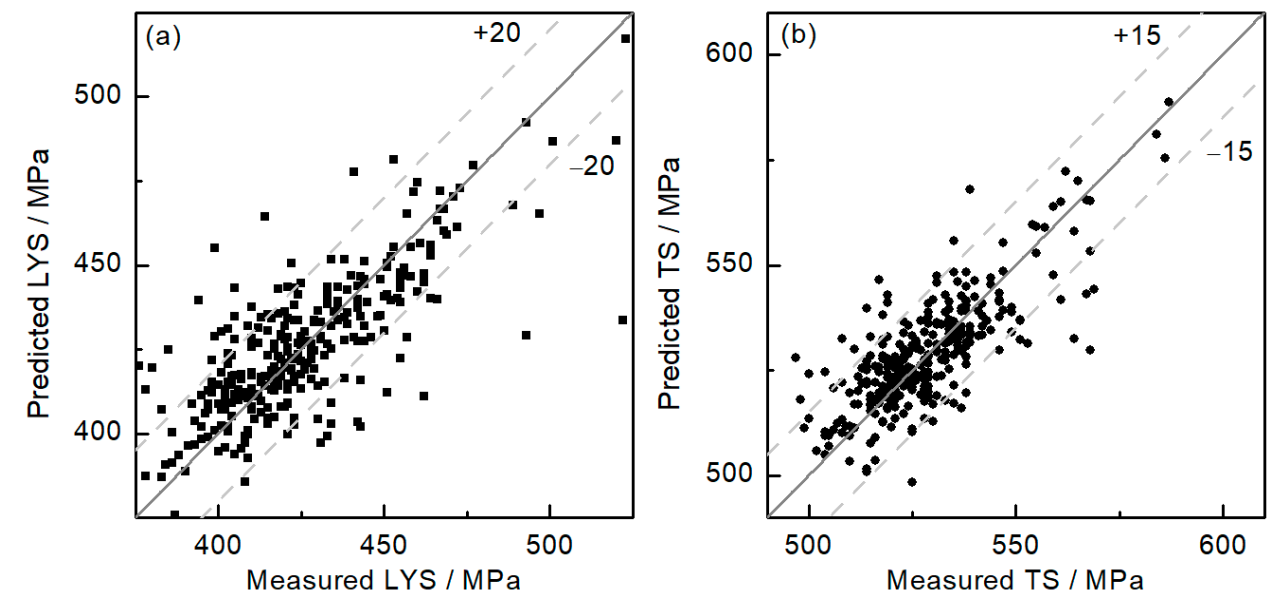

Figure 4. The prediction results of the quality prediction model: (a) LYS (lower yield strength); (b) TS (tensile strength). 


\subsubsection{Morris Sensitivity Analysis Results}

The Morris sensitivity analysis method was used to analyze the sensitivity of each input parameter of the MSVR model, and the sensitivity results are shown in Table 1. The sensitivity parameter numbers with different thresholds are shown in Figure 5. The maximum sensitivity value between LYS and TS was used as the weight coefficient in the speed control of the MPPIO model.

Table 1. Morris sensitivity results between each parameter and property index/Bit. LYS: Lower yield strength. TS: Tensile strength.

\begin{tabular}{ccc}
\hline Parameter & LYS & TS \\
\hline C & 0.15 & 0.10 \\
Mn & 0.15 & 0.13 \\
Cr & 0.22 & 0.23 \\
Mo & 0.16 & 0.15 \\
Pull Speed & 0.21 & 0.24 \\
Superheat & 0.10 & 0.11 \\
Time in Furnace & 0.17 & 0.18 \\
Split_1 & 0.18 & 0.19 \\
Reduction_1 & 0.15 & 0.14 \\
Rolling Force_1 & 0.14 & 0.13 \\
Rolling Speed_1 & 0.1 & 0.08 \\
... & $\ldots$ & $\ldots$ \\
\hline
\end{tabular}

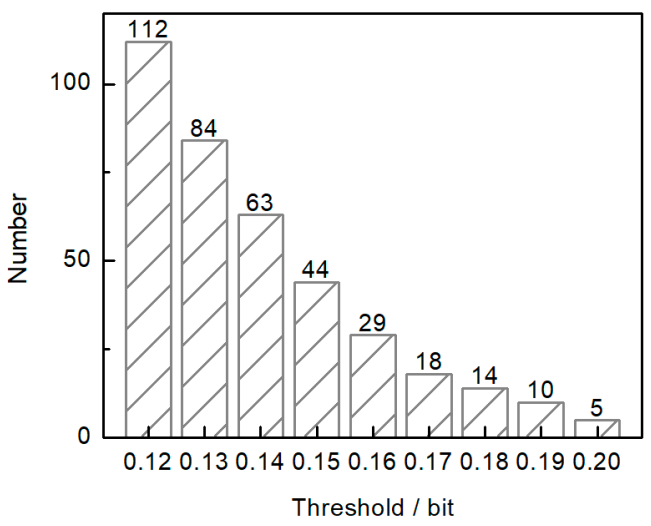

Figure 5. Sensitivity parameter numbers with different thresholds.

\subsubsection{Equipment Process Control Capability Results}

There was different equipment in the production process of steel products, when the set value was given, the equipment would have a certain probability change within a range. The process control capability plays an important role in quality control and optimization. Based on the actual data and Morris sensitivity results, the key parameters were selected for process control capability analyzing, and the component " $\mathrm{C}$ ", “Mn", " $\mathrm{Cr}^{\prime}$, , $\mathrm{S}$ ", and "Mo" and the "Reduction" of each rolling pass were taken as examples.

The different distribution functions were estimated by the maximum likelihood estimation method [29]. While fitting the random distribution functions of the key parameters, the most suitable distribution for each parameter could be directly judged according to the error of different fitting results. Taking the parameter " $\mathrm{C}$ " as an example, the fitting result is shown in Figure 6. By comparing the obtained fitting distributions, the logistic distribution was found to be the most suitable distribution for parameter " $\mathrm{C}$ ". Other process parameters also found their most suitable distribution by this method. The random distribution functions are shown in Table 2, and their fitted density curves are shown in Figure 7. 


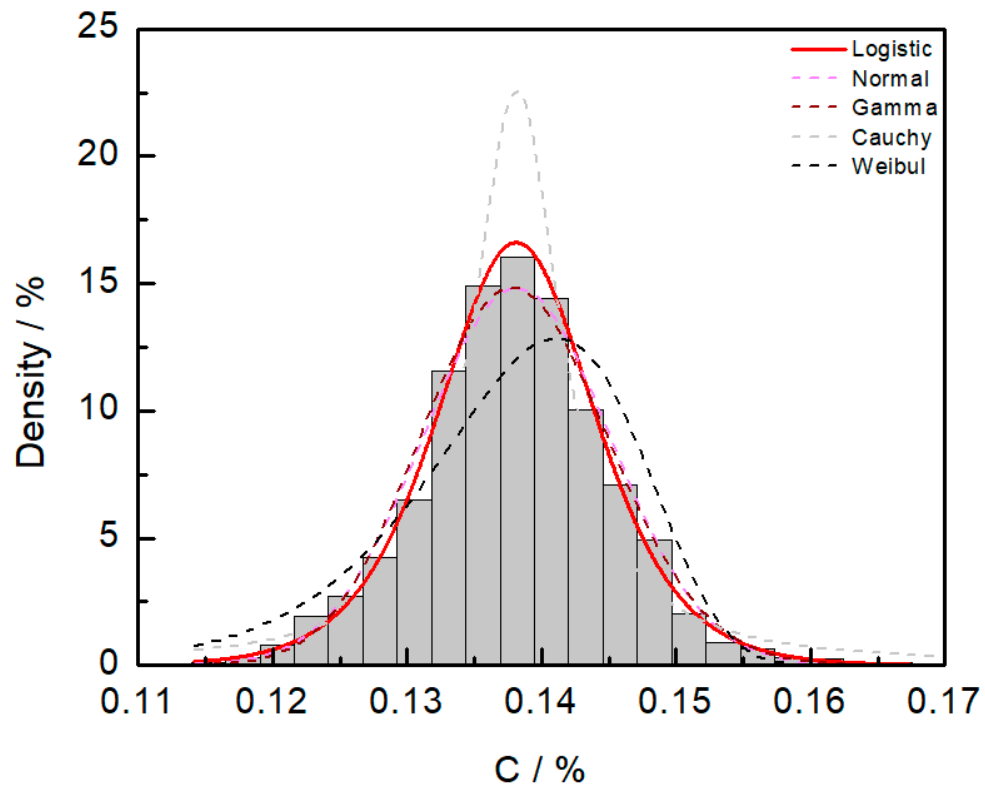

Figure 6. Different distribution fitting results of parameter " $\mathrm{C}$ ".

Table 2. Random distribution function results.

\begin{tabular}{ccc}
\hline Parameter & Distribution & Probability Density Function \\
\hline C & Logistic & $x \sim L(0.138,0.0039)$ \\
Mn & Gamma & $x \sim G(2838.22,1954.62)$ \\
Cr & Gamma & $x \sim G(20.79,848.186)$ \\
S & Normal & $x \sim N(0.00554,0.0000031)$ \\
Mo & Gamma & $x \sim G(4.58,1168.67)$ \\
\hline
\end{tabular}
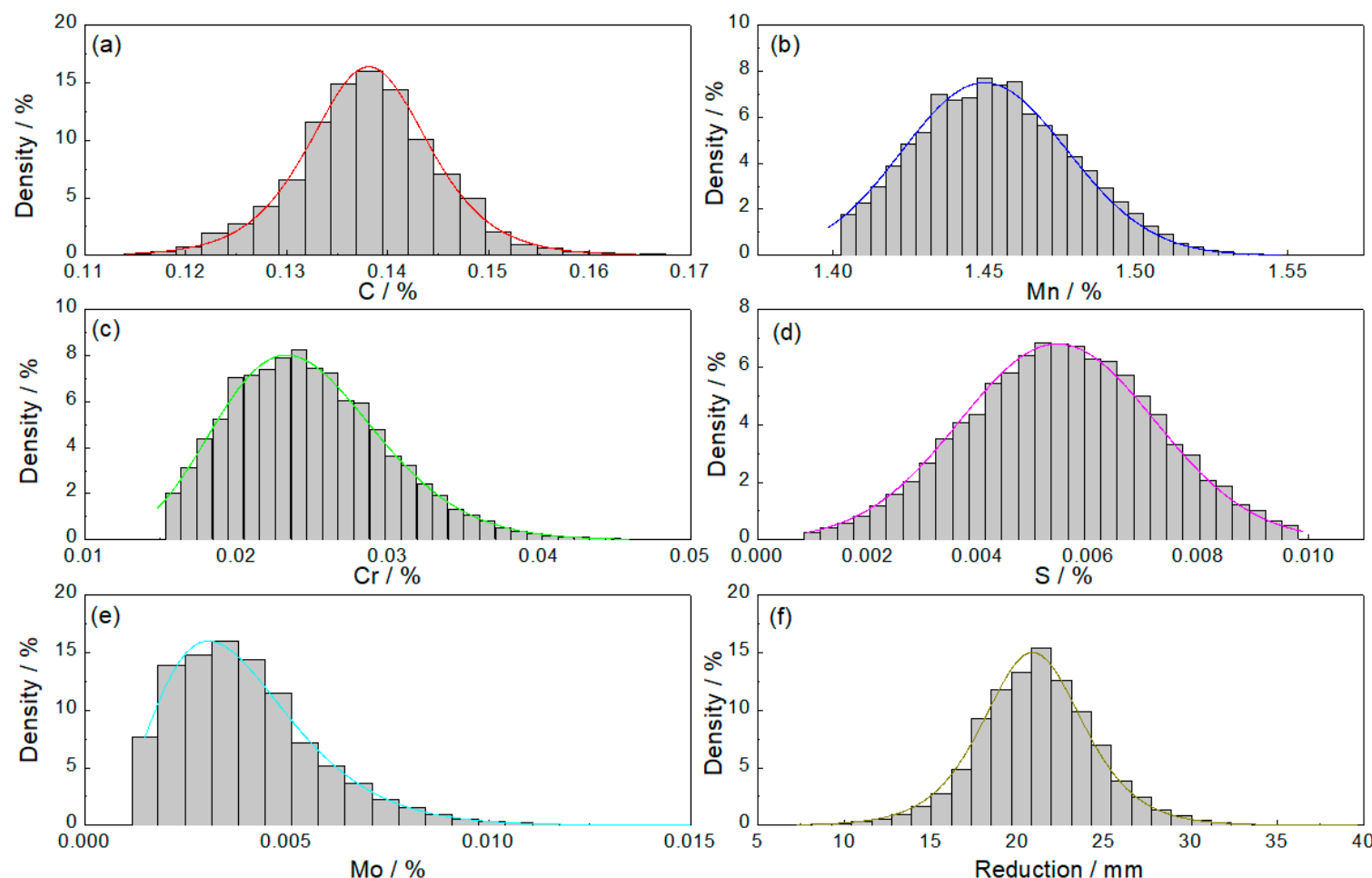

Figure 7. Fitting results of process parameter control ability: (a) C; (b) Mn; (c) Cr; (d) S; (e) Mo; (f) reduction. 
These key parameters mainly obeyed normal distribution, logistic distribution and gamma distribution, and the probability density functions are as:

$$
\begin{gathered}
f(x)=\frac{1}{\sqrt{2 \pi \sigma}} \exp \left(-\frac{(x-\mu)^{2}}{2 \sigma^{2}}\right), x \sim N\left(\mu, \sigma^{2}\right) \\
f(x)=\frac{1}{\gamma} \exp ^{-\frac{x-\mu}{\gamma}}\left(1+\exp ^{-\frac{x-\mu}{\gamma}}\right)^{2}, x \sim L(\mu, \gamma) \\
f(x)=\frac{x^{k-1}}{s^{k} \Gamma(k)} \exp ^{-s x}, x \sim G(k, s)
\end{gathered}
$$

where $\gamma>0, s>0, k>0$.

In the optimization process, the particles were randomly generated to form the relevant particle beams to analyze the processing capability results according to their parameter values and process control capability functions.

According to the process control capability functions obtained by actual fitting, the actual value probability function of the key parameter setting value in different distributions is:

$$
\begin{gathered}
f(x)=\frac{1}{\sqrt{2 \pi \sigma}} \exp \left(-\frac{\left(x-x_{\mathrm{Set}}+\mu\right)^{2}}{2 \sigma^{2}}\right), x \sim N\left(\mu, \sigma^{2}\right) \\
f(x)=\frac{1}{\gamma} \exp ^{-\frac{x-x_{\mathrm{Set}}+\mu}{\gamma}}\left(1+\exp ^{-\frac{x-x_{\mathrm{Set}}+\mu}{\gamma}}\right)^{2}, x \sim L(\mu, \gamma) \\
f(x)=\frac{\left(x+x_{\mathrm{Set}}-\frac{k}{s}\right)^{k-1}}{s^{k} \Gamma(k)} \exp \left(-s x-s x_{\mathrm{Set}}+k\right), x \sim \mathrm{G}(k, s)
\end{gathered}
$$

\subsection{Application}

Taking the design and optimization of production process parameters for four customized orders of a steel plant as an example to study the effectiveness of MIPPO model. The requirements are as shown in Table 3.

Table 3. Requirements of customized orders.

\begin{tabular}{cccccc}
\hline Order & Thickness/mm & Width/mm & Length/mm & LYS/MPa & TS/MPa \\
\hline A & 15 & 3775 & 37,000 & $400 \pm 15$ & $500 \pm 15$ \\
B & 20 & 2300 & 28,800 & $400 \pm 15$ & $500 \pm 15$ \\
C & 15 & 3775 & 37,000 & $450 \pm 15$ & $560 \pm 15$ \\
D & 22 & 3700 & 23,400 & $430 \pm 15$ & $540 \pm 15$ \\
\hline
\end{tabular}

The initial population data were randomly generated based on the order requirements. In these cases, the population size was $N=20$ and the maximum number of iterations was $S=80$. After the process control capabilities were analyzed, the 20 particles were converted into 20 particle beams. There were 100 particles in every particle beam. Take order A as an example: the initial processing capacity results are shown in Figure 8, and the processing capacity statistical results of the initial particle beam for the four orders are as shown in Table 4. Among them, the particle with the maximum fitness value (the colored curve in the figures) had the optimal processing capacity, which was taken as the $X_{\mathrm{g}}^{0}$ of the initial population. It can be seen that all the initial particle beams cannot meet the requirements. 

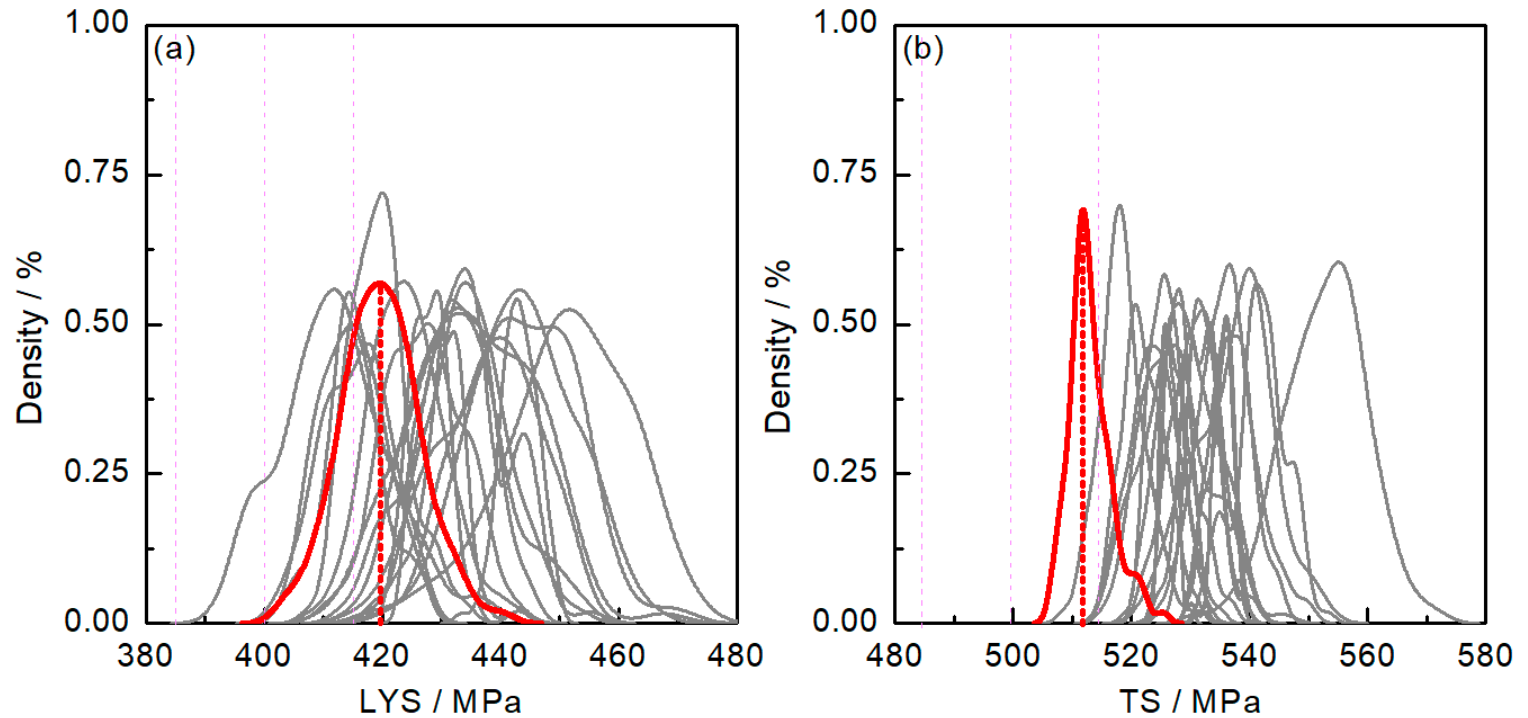

Figure 8. Processing capacity results of initial particle beam for Order A: (a) LYS; (b) TS.

Table 4. Processing capacity statistical results of the initial particle beams.

\begin{tabular}{|c|c|c|c|c|c|c|}
\hline \multirow[b]{2}{*}{ Order } & \multicolumn{3}{|c|}{ LYS } & \multicolumn{3}{|c|}{ TS } \\
\hline & $\begin{array}{l}\text { Processing } \\
\text { Capacity } / \%\end{array}$ & $\begin{array}{l}\text { Max Capacity } \\
\text { Point/MPa }\end{array}$ & $\begin{array}{l}98 \% \text { Capacity } \\
\text { Range/MPa }\end{array}$ & $\begin{array}{l}\text { Processing } \\
\text { Capacity/\% }\end{array}$ & $\begin{array}{l}\text { Max Capacity } \\
\text { Point/MPa }\end{array}$ & $\begin{array}{c}98 \% \text { Capacity } \\
\text { Range/MPa }\end{array}$ \\
\hline A & 24.91 & 420 & 403,438 & 75.02 & 512 & 506,524 \\
\hline B & 80.09 & 390 & 372,408 & 99.86 & 499 & 492,512 \\
\hline $\mathrm{C}$ & 80.76 & 448 & 425,480 & 71.66 & 548 & 535,564 \\
\hline $\mathrm{D}$ & 79.91 & 435 & 409,459 & 98.5 & 545 & 522,558 \\
\hline
\end{tabular}

After several iterations, the production process parameter results that meet the requirements of each order were obtained by the MIPPO model. The processing capacity results of the final particle beam for Order A are shown in Figure 9, and the processing capacity statistical results of the final particle beam for the four orders are as shown in Table 5.
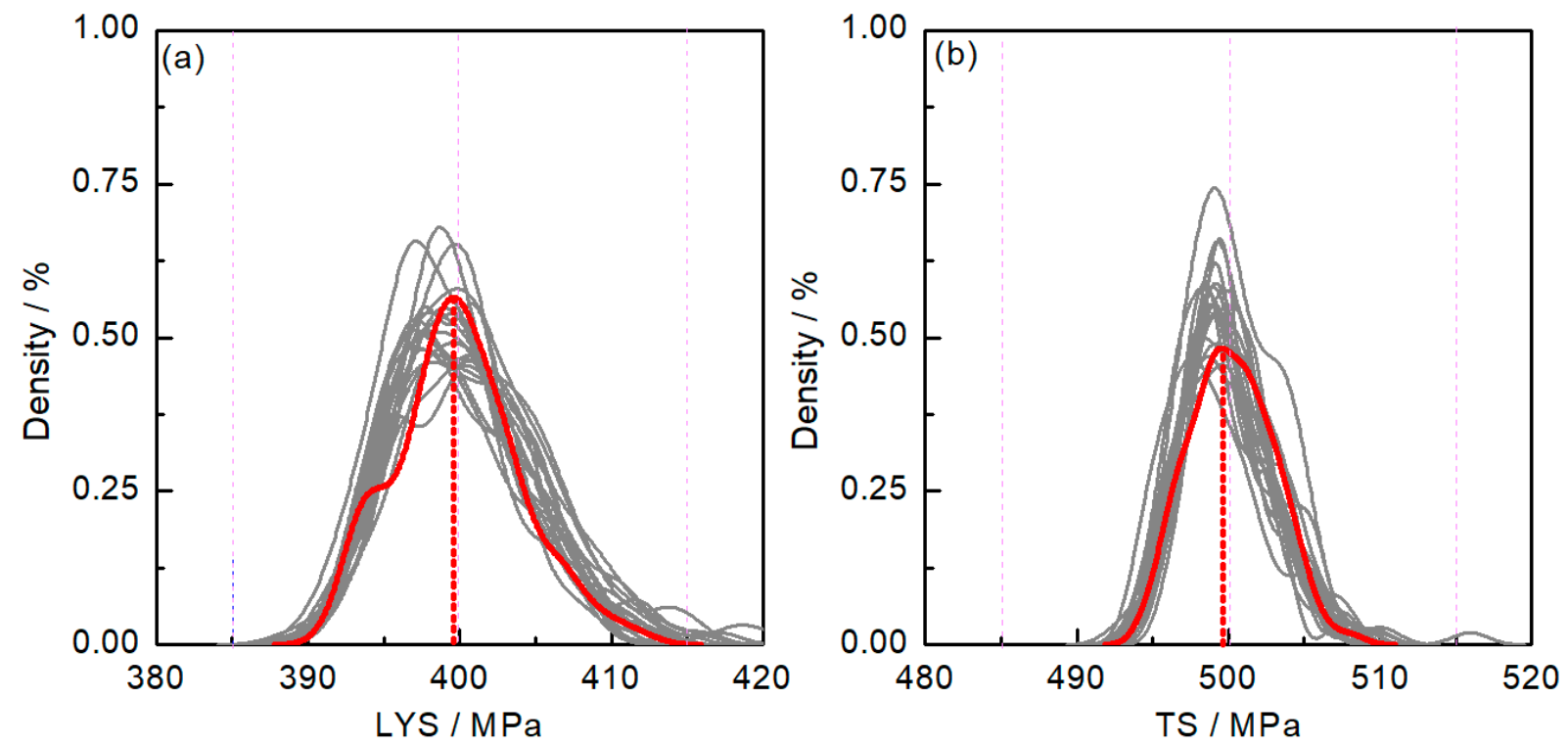

Figure 9. Processing capacity results of final particle beam for Order A: (a) LYS; (b) TS. 
Table 5. Processing capacity statistical results of the final particle beams.

\begin{tabular}{ccccccc}
\hline \multirow{2}{*}{ Order } & \multicolumn{3}{c}{ LYS } & \multicolumn{2}{c}{ TS } \\
\cline { 2 - 7 } & $\begin{array}{c}\text { Processing } \\
\text { Capacity/\% }\end{array}$ & $\begin{array}{c}\text { Max Capacity } \\
\text { Point/MPa }\end{array}$ & $\begin{array}{c}\mathbf{9 8 \%} \text { Capacity } \\
\text { Range/MPa }\end{array}$ & $\begin{array}{c}\text { Processing } \\
\text { Capacity/\% }\end{array}$ & $\begin{array}{c}\text { Max Capacity } \\
\text { Point/MPa }\end{array}$ & $\begin{array}{c}\mathbf{9 8} \% \text { Capacity } \\
\text { Range/MPa }\end{array}$ \\
\hline A & 99.98 & 400 & 391,411 & 100 & 500 & 494,507 \\
B & 100 & 400 & 388,410 & 100 & 500 & 493,508 \\
C & 99.68 & 450 & 436,462 & 100 & 559 & 551,568 \\
D & 100 & 430 & 422,437 & 100 & 540 & 534,546 \\
\hline
\end{tabular}

The parameter optimization results of the four orders were all able to meet customized requirements. A part of key process parameter processing control windows for the four orders are shown in Figure 10. The optimized results were used as scheduling guidance in the actual production process.
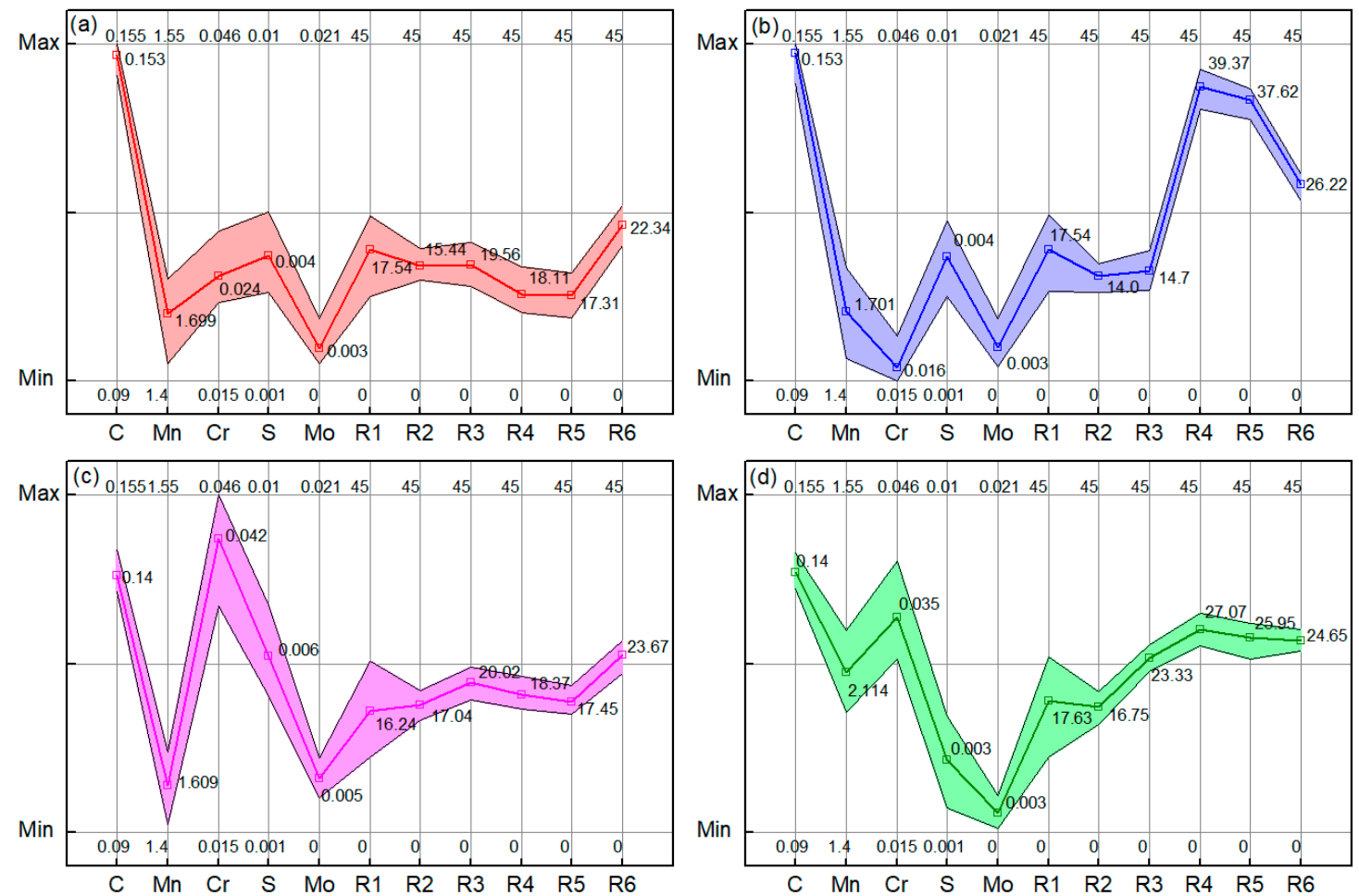

Figure 10. The key process parameter processing control windows: (a) Order A; (b) Order B; (c) Order C; (d) Order D. R1 is the reduction of the first pass. R2 is the reduction of the second pass. R3 is the reduction of the third pass. R4 is the reduction of the fourth pass. R5 is the reduction of the fifth pass and R6 is the reduction of the sixth pass.

The MIPPO model comprehensively evaluated the geometric size and mechanical property requirements of the order, and further optimized the parameter values and processing control windows after generating the initial population based on historical production data. Order B and Order A had the same property requirements but different geometric size requirements, and their final results had similar composition results, but the rolling process parameters were specific; Order $\mathrm{C}$ and Order A had the same geometric size requirements but different property requirements. In their final results, the process parameters of the rolling stage were similar, but the composition results were significantly different; the geometric size and property requirements of Order D were different from other orders, and the composition results and rolling parameters were also significantly different in its final results. The process parameter optimization results of these four orders all had a reasonable processing control window, and it proved that the MIPPO model had 
a good effect in the multi-objective process parameter interval optimization problem for customized production.

\section{Discussion}

To find out the difference between the traditional point optimization problem and interval optimization problem, the traditional PSO method was used to optimize the process parameters that meet the Order A. Its population size is 20 as well as MPPIO. The mechanical property prediction results of each final particle in traditional PSO method are shown in Figure 11.

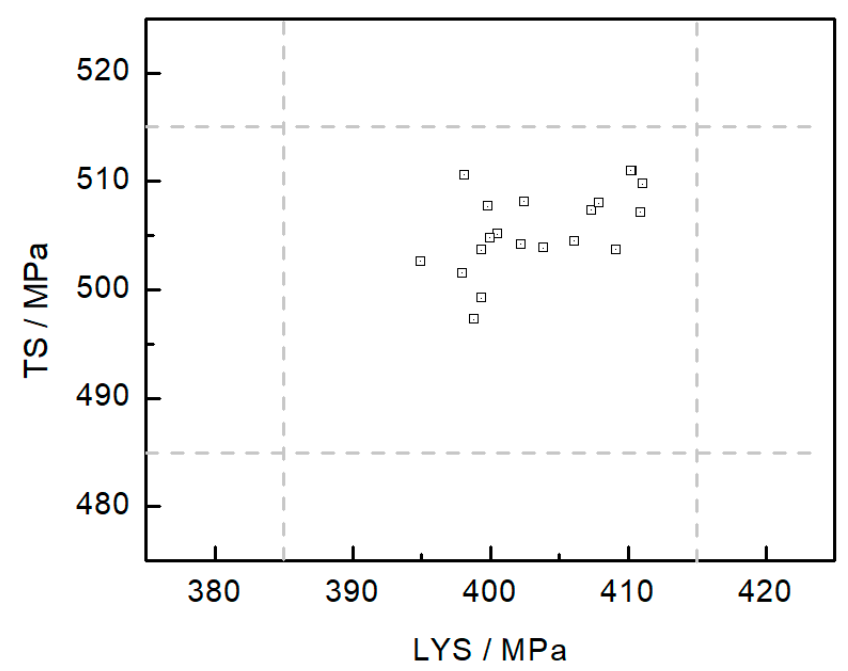

Figure 11. Mechanical property prediction results of final population in traditional PSO (particle swarm optimization).

In the traditional PSO method without equipment process control capability, the obtained parameter prediction results could only reflect the possible predicted values and could not give a clear degree of reliability that fallen within a given range. As comparison, the final optimal parameter results obtained by the traditional PSO method were analyzed for the processing capability, and the results are shown in Figure 12.
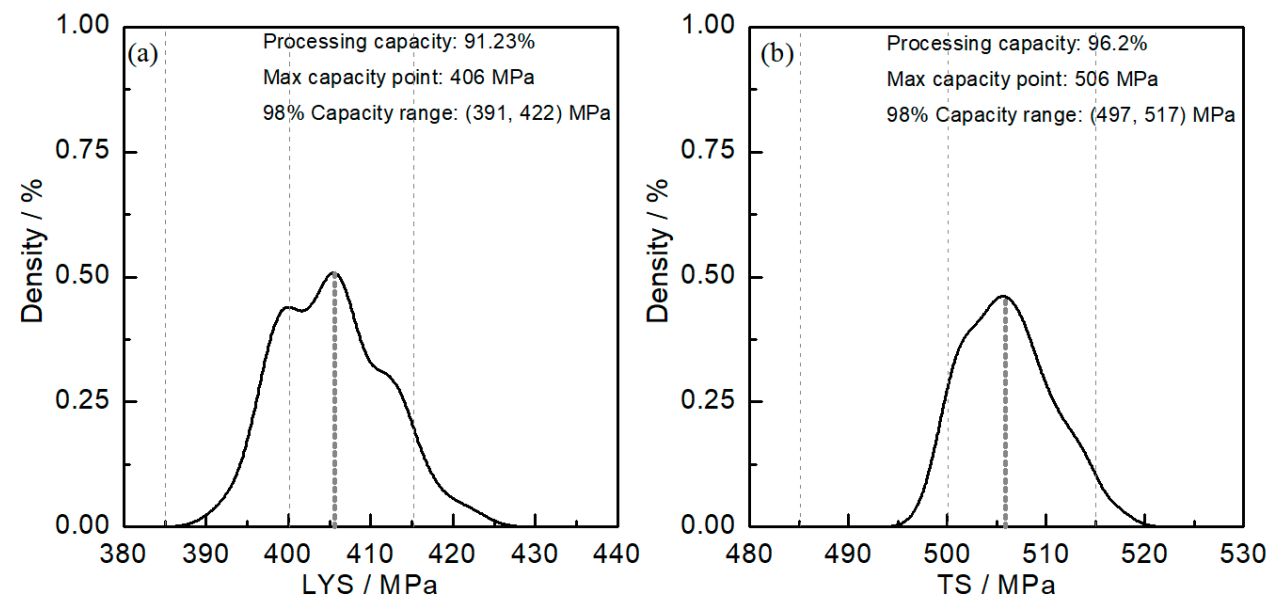

Figure 12. Processing capacity results of final population in traditional PSO: (a) LYS; (b) TS.

The final optimization results of the traditional PSO method could not reach the requirements of the Order A. According to the results, the processing capacity of LYS and TS were $91.23 \%$ and $96.2 \%$, respectively. The maximum capacity points of LYS and TS were $406 \mathrm{MPa}$ and $506 \mathrm{MPa}$, respectively, which had a deviation from the requirements 
and could not be able to effectively solve the orders with stricter scope requirements. The optimal solutions of MPPIO had better stability, which could provide more optimized parameter selections.

\section{Conclusions}

In this paper, we proposed a multi-objective process parameter interval optimization model (MPPIO) for customized production of steel products. The control capability constraints and sensitivity analysis are added in the process parameters optimization. On the one hand, the traditional point optimization problem is transformed into an interval optimization problem, and on the other hand, it also improves the optimization ability and convergence speed of the model.

The MSVR method was used as a verification in the optimization process to ensure that the optimization results could meet the requirements of multiple property indicators at the same time. By combining the equipment process control capability constraint and Morris sensitivity weighted control, the original property quality optimization was transformed into processing capacity interval optimization and accelerated the iteration processing and improved the optimization ability. Practical applications proved that not only can the MPPIO model ensure that the optimization results meet the customization requirements of multiple property indicators at the same time, but also the optimal parameter processing control window can be obtained, which improved the quality control ability of the enterprise. This is not possible with traditional process parameter optimization methods.

There are two important issues our future work will focus on. Firstly, the process control capability constraints analysis is needed for more parameters to improve the processing capability interval accuracy; secondly, we will develop new optimization algorithms to solve more complex optimization problem.

Author Contributions: Conceptualization, Z.L. and Y.Y.; methodology, Y.Y.; data curation, Y.Y. and Z.L.; funding acquisition, Z.L.; software, Y.Y.; validation, Y.Y.; visualization, Y.Y.; writing —original draft, Y.Y.; writing - review and editing, Y.Y. and Z.L. All authors have read and agreed to the published version of the manuscript.

Funding: This work was funded by Fundamental Research Funds for the Central Universities, grant number FRF-MP-20-08.

Conflicts of Interest: The authors declare no conflict of interest.

\section{References}

1. Gajdzik, B.; Sroka, W. Resource Intensity vs. Investment in Production Installations-The Case of the Steel Industry in Poland. Energies 2021, 14, 443. [CrossRef]

2. Indrawati, S.; Azzam, A.; Ramdani, A.C. Manufacturing Efficiency Improvement through Lean Manufacturing Approach: A Case Study in A Steel Processing Industry. IOP Conf. Series: Mater. Sci. Eng. 2019, 598, 012062. [CrossRef]

3. Zhang, H.; Liu, Q.; Chen, X.; Zhang, D.; Leng, J. A digital twin-based approach for designing and multi-objective optimization of hollow glass production line. IEEE Access 2017, 5, 26901-26911. [CrossRef]

4. Kwon, S.-H.; Hong, D.-G.; Yim, C.-H. Prediction of hot ductility of steels from elemental composition and thermal history by deep neural networks. Ironmak. Steelmak. 2020, 47, 1176-1187. [CrossRef]

5. Hore, S.; Das, S.K.; Banerjee, S.; Mukherjee, S. An adaptive neuro-fuzzy inference system-based modelling to predict mechanical properties of hot-rolled TRIP steel. Ironmak. Steelmak. 2017, 44, 656-665. [CrossRef]

6. Li, W.-g.; Xie, L.; Zhao, Y.-t.; Li, Z.-x.; Wang, W.-b. Prediction model for mechanical properties of hot-rolled strips by deep learning. J. Iron Steel Res. Int. 2020, 27, 1045-1053. [CrossRef]

7. Xing, S.; Ju, J.; Xing, J. Research on hot-rolling steel products quality control based on BP neural network inverse model. Neural Comput. Appl. 2019, 31, 1577-1584. [CrossRef]

8. Serra, R.; Chibane, H.; Duchosal, A. Multi-objective optimization of cutting parameters for turning AISI 52100 hardened steel. Int. J. Adv. Manuf. Technol. 2018, 99, 2025-2034. [CrossRef]

9. Rao, R.V.; Rai, D.P.; Balic, J. A multi-objective algorithm for optimization of modern machining processes. Eng. Appl. Artif. Intell. 2017, 61, 103-125. [CrossRef]

10. Wang, S.; Chiang, J.-Y.; Tsai, T.-R.; Qin, Y. Robust process capability indices and statistical inference based on model selection. Comput. Ind. Eng. 2021, 156, 107265. [CrossRef] 
11. Lee, C.-H.; Chen, C.-H.; Lin, C.; Li, F.; Zhao, X. Developing a quick response product configuration system under industry 4.0 based on customer requirement modelling and optimization method. Appl. Sci. 2019, 9, 5004. [CrossRef]

12. Wu, S.-w.; Zhou, X.-g.; Ren, J.-k.; Cao, G.-m.; Liu, Z.-y.; Shi, N.-a. Optimal design of hot rolling process for C-Mn steel by combining industrial data-driven model and multi-objective optimization algorithm. J. Iron Steel Res. Int. 2018, 25, 700-705. [CrossRef]

13. Chen, Z.; Li, X.; Wang, L.; Zhang, S.; Cao, Y.; Jiang, S.; Rong, Y. Development of a hybrid particle swarm optimization algorithm for multi-pass roller grinding process optimization. Int. J. Adv. Manuf. Technol. 2018, 99, 97-112. [CrossRef]

14. Babu, K.K.; Panneerselvam, K.; Sathiya, P.; Haq, A.N.; Sundarrajan, S.; Mastanaiah, P.; Murthy, C.S. Parameter optimization of friction stir welding of cryorolled AA2219 alloy using artificial neural network modeling with genetic algorithm. Int. J. Adv. Manuf. Technol. 2018, 94, 3117-3129. [CrossRef]

15. Haber, R.E.; Beruvides, G.; Quiza, R.; Hernandez, A. A simple multi-objective optimization based on the cross-entropy method. IEEE Access 2017, 5, 22272-22281. [CrossRef]

16. Mohammadi, M.; Lakestani, M.; Mohamed, M. Intelligent parameter optimization of savonius rotor using artificial neural network and genetic algorithm. Energy 2018, 143, 56-68. [CrossRef]

17. Aboutaleb, A.M.; Tschopp, M.A.; Rao, P.K.; Bian, L. Multi-objective accelerated process optimization of part geometric accuracy in additive manufacturing. J. Manuf. Sci. Eng. 2017, 139, 101001. [CrossRef]

18. Yan, Y.-f.; Lü, Z.-m. Multi-objective quality control method for cold-rolled products oriented to customized requirements. Int. J. Miner. Metall. Mater. 2021, 28, 1332-1342. [CrossRef]

19. Wang, G.; Guo, L. A novel hybrid bat algorithm with harmony search for global numerical optimization. J. Appl. Math. 2013, 2013, 1-21. [CrossRef]

20. Wu, Y.; Yan, Y.; Lv, Z. Novel Prediction Model for Steel Mechanical Properties with MSVR Based on MIC and Complex Network Clustering. Metals 2021, 11, 747. [CrossRef]

21. Zhang, X.; Kano, M.; Tani, M.; Mori, J.; Ise, J.; Harada, K. Hurdle modeling for defect data with excess zeros in steel manufacturing process. IFAC-PapersOnLine 2018, 51, 375-380. [CrossRef]

22. Sui, X.; Lv, Z. Prediction of the mechanical properties of hot rolling products by using attribute reduction ELM. Int. J. Adv. Manuf. Technol. 2016, 85, 1395-1403. [CrossRef]

23. Zhou, P.; Guo, D.; Chai, T. Data-driven predictive control of molten iron quality in blast furnace ironmaking using multi-output LS-SVR based inverse system identification. Neurocomputing 2018, 308, 101-110. [CrossRef]

24. Zhang, Y.; Li, H.-G.; Wang, Q.; Peng, C. A filter-based bare-bone particle swarm optimization algorithm for unsupervised feature selection. Appl. Intell. 2019, 49, 2889-2898. [CrossRef]

25. Ye, W.; Feng, W.; Fan, S. A novel multi-swarm particle swarm optimization with dynamic learning strategy. Appl. Soft Comput. 2017, 61, 832-843. [CrossRef]

26. Cho, J.-H.; Wang, Y.; Chen, R.; Chan, K.S.; Swami, A. A survey on modeling and optimizing multi-objective systems. IEEE Commun. Surv. Tutor. 2017, 19, 1867-1901. [CrossRef]

27. Feng, K.; Lu, Z.; Yang, C. Enhanced Morris method for global sensitivity analysis: Good proxy of Sobol'index. Struct. Multidiscipl. Optim. 2019, 59, 373-387. [CrossRef]

28. Likhachev, D. Parametric sensitivity analysis as an essential ingredient of spectroscopic ellipsometry data modeling: An application of the Morris screening method. J. Appl. Phys. 2019, 126, 184901. [CrossRef]

29. Piao, C.; Zhi-Sheng, Y. A systematic look at the gamma process capability indices. Eur. J. Oper. Res. 2018, 265, 589-597. 